\title{
Effects of cranial osteopathic techniques in the symptoms of benign positional paroxistic vertical
}

\author{
Otávio Augusto do Nascimento Oliveira ${ }^{1}$, Laiana Sepúlveda de Andrade Mesquita ${ }^{2}$, Maurício Rocha Mendes ${ }^{3}$, Lílian \\ Maria Magalhães Costa de Oliveira ${ }^{4}$, Laís Cristina Almeida ${ }^{5}$.
}

${ }^{1}$ Brazilian School of Osteopathy, Recife (PE), Brazil, ${ }^{2}$ Department of Physiotherapy, State University of Piauí, Teresina (PI), Brazil, ${ }^{3}$ Brazilian School of Osteopathy, Recife (PE), Brazil, ${ }^{4}$ Department of Physiotherapy, State University of Piauí, Teresina (PI), Brazil, ${ }^{5}$ Brazilian School of Osteopathy, Belo Horizonte (MG), Brazil.

\section{ABSTRACT}

Background: The benign paroxysmal positional vertigo (BPPV) is the most common cause of dizziness among the population. The osteopathyis a practice of manual therapy which is guided by a holistic perspective of human being, the cranial osteopathy affirms that the respective bones of the cranium represent mobility. Objective: To investigate the effect of the cranial osteopathy techniques on the benign paroxysmal positional vertigo. Methods: The current study included 20 female subjects, each one of them with benign paroxysmal positional vertigo, distributed in two groups, an intervention group and a control group (placebo); in order to detect the BPPV, was applied the Dix-Hallpike test before and after the interventions. Three techniques of cranial osteopathy were used on the structures related to vestibule and to the temporal bones: mobilization of temporal bones, tensioning of cerebellar tentorium and mobilization of eyeball. All statistical analyzes were performed using the GraphPad Prism 6.0 software (GraphPad Software, CA). Results: Among the intervention group, 7 of 10 individuals were negative to the Dix-Hallpike test, whilst individuals of the control group remained positive to the test. In the statistical analysis verified that the intervention with osteopathic techniques had a significant effect in compared to the control group, with a value $p=0.0261$. Conclusion: The cranial osteopathy appears to be able of produce effects on the vestibular activity, whereas were able to reduce, in a significant means, the symptoms concerning to BPPV.

Trial registration: NCT03854084

Keywords: Osteopathic Medicine; Benign Paroxysmal Positional Vertigo; Vertigo; Vestibule.

\section{BACKGROUND}

Vertigo is a type of dizziness in which there is spatial disorientation of rotational character ${ }^{(1)}$. Benign paroxysmal positional vertigo (BPPV) is the most common cause of dizziness among the population, characterized by short-lived vertiginous outbreaks resulting from positional changes in the head ${ }^{(2,3)}$ and the presence of positional nystagmus due to these changes ${ }^{(4)}$, which may come accompanied by nausea ${ }^{(5)}$. The pathophysiology of BPPV involves the displacement of calcium carbonate crystals (otoliths) from the utricle to one of the three semicircular canals (anterior, posterior or lateral) - ductolithiasis - or their adherence to the dome of the canals - cupololithiasis ${ }^{(6,7)}$.The DixHallpike test is used for the diagnosis of BPPV and, in positive case, after the test, the patient presents nystagmus ${ }^{(8,9)}$. Thus, due to the movement of the otoliths, the treatment consists basically in repositioning maneuvers ${ }^{(10)}$.

Osteopathy is a practice of manual therapy that guided by a holistic vision of the human being, based on four principles: 1 ) the body is a unit, 2) it is capable of self-regulation, cure and health maintenance, 3) structure and function are reciprocally inter-related, and 4) treatment should be based on the three principles above $^{(11)}$. Cranial osteopathy, created by Sutherland, states that the individual bones of the skull reflect mobility, that fundaments the primary respiratory mechanism manifested through the movement of the skull bones, sacrum, dural membranes, central nervous system, and cerebrospinal fluid ${ }^{(12)}$.

There is evidence that cranial dysfunctions of the internal / external rotating temporal bones may modify the orientation of the semicircular canals, causing vertigo $^{(13)}$, and that eyeball mobilizations can be a sensory stimulus of the vestibulo-ocular pathways, as they help to balance tone of the extraocular muscles and cause fascial influences on the optic nerve and the oculomotor and thus stimulates the vestibular nuclei; there is also the proposition that the tension of the cerebellar tent and the mobilization of the temporal bones have influences on the structures that comprise the vestibule $^{(14)}$. Thus, the aim of this study is to investigate the effect of cranial osteopathic techniques on Benign Paroxysmal Positional Vertigo. 


\section{METHODS}

This research used a longitudinal, prospective, experimental and qualitative methodology, performed at a physiotherapy clinic. The present research was submitted and approved by the Research Ethics Committee of the State University of Piauí (UESPI), with number 2.439.677. This study was conducted in accordance to Resolution №. 466/12 of the National Health Council (CNS). To execution of the study, the volunteers or their responsible read and signed an written informed consent form (WICF). The sample was the of random type and included 20 women with BPPV, aged 25 to 45 years, from nosological test, randomly allocated in a control group and an intervention group. As exclusion criteria were adopted the use of any medication to treat vertigo and / or the presence of any infectious pathology or deformity in the inner ear Each one of the individuals from both groups was submitted to 10 interventions and the Dix-Hallpike test ${ }^{(15)}$. All test stages should be performed at 40 -second intervals.

The test was performed before and after treatment to test the good inter-relation of visual and proprioceptive functions related to the vestibule, besides being a parameter for the diagnosis of benign paroxysmal positional vertigo. The patients were submitted to the following techniques $\left.{ }^{(14)}: 1\right)$ Sutherland technique of temporal bones in favor of free movement (Figure 01): external and internal rotation movement of temporal bones is tested on each side. To test the external rotation (RE) pushes the zygomatic process in the caudal, anterior and lateral direction. The mastoid process is pushed in the medial, cephalic and anterior direction. The opposite is realized to test internal rotation (RI).

After the tests, identifies what is the free and restricted rotation in each temporal bone; 2 ) Sutherland technique of temporal bones in favor of restricted movement (Figure 01): the same tests of the previous technique are performed, but after gradually and slowly administer the restricted rotation movement of each bone rotation almotion of each bone, repeating the procedure until the tensions decrease; 3) Ear Pull Technique (Figure 02): a gradual impulse is performed and slowly pulling the ears in the posterior and lateral direction until the tension decrease and resume the initial position, slowly and gradually.

Repeated the procedure until tensions decrease; 4) Ruddy's technique (Figure 03): Slow and gradual pressure is performed on each eyelid of the eyeball until the tension decreases and slowly and gradually returns to its initial position. The procedure is repeated until the tensions decrease. For the control group, was only used a simulation of the techniques used in the intervention group.

All statistical analyses were performed using Graphpad prism 6.0 software (GraphPad Software, CA). In addition, fisher's exact test was used to assess whether patients, after intervention by cranial osteopathic techniques, presented improvements with statistical significance in relation to the control group. The data were evaluated from the number of individuals from both groups, by the Dix-hallpike test at the end of the interventions. Finally, all the hypotheses tested were performed considering the $p$ value of $<0.05$ as significant for analysis.

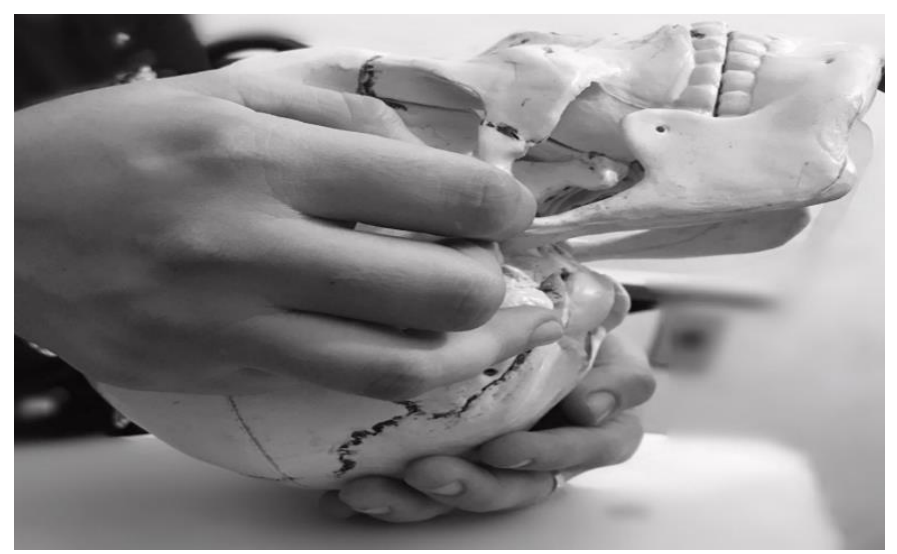

Figure 1. Exemplification of the temporal bone rotation technique

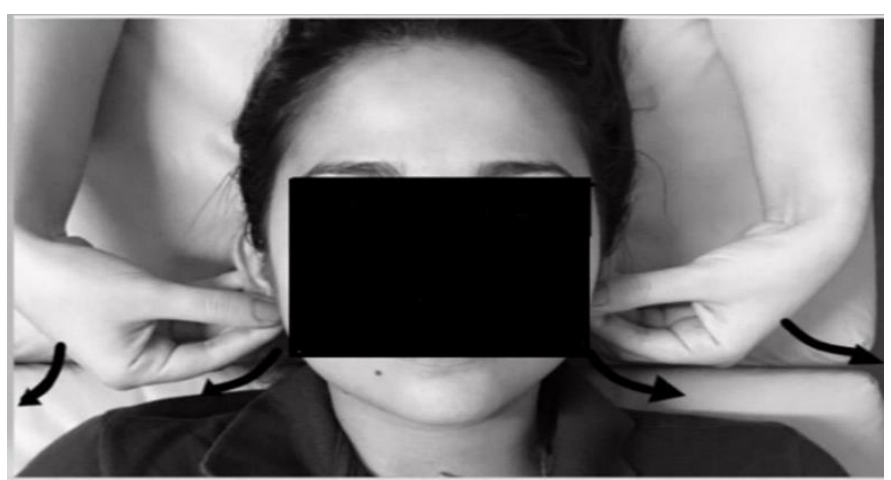

Figure 2. Exemplification of the "Ear pull" technique

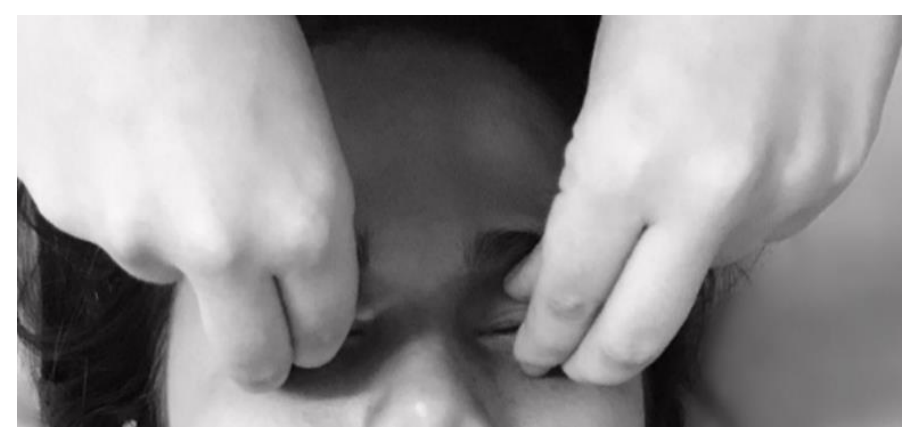

Figure 3. Global technique for eyeball 


\section{RESULTS}

The study included 20 female individuals in the intervention group $(n=10)$ the mean age was 34.1 years, already in the control group $(n=10)$ the mean age was 32.4 years, the characterization of the sample is described in table 01. After the ten interventions in the control group, the ten individuals continued to show the positive Dix-Hallpike test, in the intervention group, only three (Table 02).

In the statistical analysis verified that the intervention with osteopathic techniques had a significant effect in compared to the control group, with a value $p=0.0261$. Also In relation to the intervention group, the 3 individuals who still presented the positive Dix-Hallpike test reported improvement of the vertigo symptoms. While in the control group, 2 individuals reported improvement in vertigo despite the DixHallpike test remaining positive. These relationships were not included in the statistical evaluations.

Table 01. Characterization of patients

\begin{tabular}{lll}
\hline & $\begin{array}{l}\text { Intervention } \\
\text { group }\end{array}$ & Control group \\
\hline Middle Ages & 34.1 & 32.4 \\
Mean BMI & 26.24 & 26.88 \\
\hline
\end{tabular}

Table 02. Comparison between groups

\begin{tabular}{lcc}
\hline & $\begin{array}{c}\text { Intervention } \\
\text { group }\end{array}$ & Control group \\
\hline $\begin{array}{l}\text { Positive Dix- } \\
\text { Hallpike after } \\
\text { intervention }\end{array}$ & 3 & 10 \\
$\begin{array}{l}\text { Positive Dix- } \\
\text { Hallpike after } \\
\text { intervention } \\
\text { with symptom } \\
\text { improvement }\end{array}$ & 3 & 2 \\
\hline
\end{tabular}

\section{DISCUSSION}

Benign paroxysmal positional vertigo is widely accepted as the main cause of vertigo triggered by postural change of the head and the Dix-Hallpike test is considered the gold standard for the diagnosis of BPPV $^{(16-18)}$.

In the intervention group, the three who reported a positive test at the end of treatment reported having improvements in the vertiginous case. It has been found that cranial osteopathy was able to positively influence the ocular vestibule reflex, once Dix Hallpike's maneuver tests the good interrelation of visual and proprioceptive functions related to the vestibule, cause the correct interpretation of eye movements is crucial to obtain an accurate diagnosis of the affected canal and the laterality of the disease $\mathrm{e}^{(19,20)}$.

Despite all in the control group presented a positive test after intervention, two reported improvement in vertigo symptoms. Thus, we found that placebo effect was not able to significantly changes the vertiginous sensation caused by BPPV, although several studies have shown that the effect is capable of reducing clinical manifestations.

Since there are positive responses from patients in relation to placebo due to the influence of psychosocial factors, including the expectation that induce neuropsychological mechanisms, such as conditioning, expectation and reward, triggering changes in brainbody interactions through endocrine, immunological and autonomous systems ${ }^{(21)}$, factors that can justify improving the symptoms of these patients.

And the fact that some individuals in the intervention group still present BPPV can be explained by the fascial relationships and the autonomic nervous system, cause an increase in tone of cervical muscles or the entire posterior muscle chain is observed in patients with $\mathrm{BPPV}^{(22,23)}$. Emotional factors could also be associated with pathology, highlighting the psychological, neurological and muscular influences on the vestibule through the vestibular-spinal vias ${ }^{(24)}$.

Ruffini and Pacini's corpuscles are mechanoreceptors commonly found in fascia, and the pressure applied to these can stimulate the nervous system and provide a reduction of the muscle tension ${ }^{(25)}$. Therefore, the results obtained with cranial osteopathic techniques could not be explained exclusively by mechanical properties, but also by the association of mechanical, neuromuscular and autonomic nervous system characteristics ${ }^{(26-29)}$.

As for the individuals submitted to this research, it was possible to establish the predominance of BPPV in female individuals, a fact that goes to other studies that point the women as more susceptible than men to otoneurological alterations, due your hormonal changes $^{(30)}$. 


\section{CONCLUSION}

Cranial osteopathy in this study was able to produce effects on vestibular activity with the capacity of reduction in symptoms related to BPPV, having more representative improvements in the intervention group than in the control after the Dix-Hallpike test, deducing that cranial osteopathic maneuvers were able to positively influence the vestibule-ocular reflex.

It is suggests the development of new studies regarding the effects cranial osteopathy in BPPV in male individuals for analysis and comparison of the results obtained in this study, since female individuals were predominant.

AUTHORS' CONTRIBUTIONS: OANO: study design, data collection and article writing; LSAM: article writing and article review; MRM: study design and article review; LMMCO: article writing and article review, LCA: study design and article review.

FINANCIAL SUPPORT: Nothing to declare.

CONFLICT OF INTEREST: The authors declare that there was no conflict of interests.

\section{REFERENCES}

1. Manso A, Ganança MM, Caovilla HH. Vestibular rehabilitation with visual stimuli in peripheral vestibular disorders. Braz J Otorhinolaryngol. 2016;82:232-241.

2. Maslovara S, Soldo SB, Sestak A, Milinkovic K, Rogicnamacinski J, Soldo A. $25(\mathrm{OH})$ D3 levels, incidence and recurrence of different clinical forms of benign paroxysmal positional vertigo. Braz J Otorhinolaryngol. 2018;84: 453-459.

3. Bhattacharyya N, Gubbels SP, Schwartz SR, Edlow $J A$, El-Kashlan $H$, Fife $T$ et al. Clinical Practice Guideline : Benign Paroxysmal Positional Vertigo ( Update ). OTO Open. 2017;156(3):S1-S47.

4. Imai T, Takeda N, Ikezono T, Shigeno K, Asai M, Watanabe $Y$ et al. Classification, diagnostic criteria and management of benign paroxysmal positional vertigo. Auris Nasus Larynx. 2017;44(1):1-6.

5. Ferreira MM, Ganança MM, Caovilla HH. Subjective visual vertical after treatment of benign paroxysmal positional vertigo. Braz J Otorhinolaryngol. 2017;83(6):659-664.

6. André APR, Moriguti JC, Moreno NS. Conduct after Epley's maneuver in elderly with posterior canal BPPV in the posterior canal. Braz J Otorhinolaryngol. 2010;76(3):300-5.
7. Korkmaz M, Korkmaz H. Cases requiring increased number of repositioning maneuvers in benign paroxysmal positional vertigo. Braz J Otorhinolaryngol. 2016;82(4):452-457.

8. Burston A, Mossman S, Weatherall M. Are there diurnal variations in the results of the Dix-Hallpike manoeuvre? J Clin Neurosci. 2012;19(3):415-7.

9. Muncie HL, Sirmans SM, James E. Dizziness: Approach to Evaluation and Management. Am Fam Physician. 2017;95(3):154-162.

10. Karle PM, Fernández RL, Bahamonde SH. Subjective benign paroxysmal positional vertigo. Rev Otorrinolaringol Cir Cabeza Cuello. 2014;74(3):283286.

11. Fahlgren E, Nima AA, Archer T, Garcia D. Personcentered osteopathic practice: patients personality (body, mind, and soul) and health ( ill-being and wellbeing). PeerJ. 2015;3:e1349.

12. Jäkel A, Hauenschild PV. Therapeutic Effects of Cranial Osteopathic Manipulative Medicine: A Systematic Review. J Am Osteopath Assoc. 2011; 111(12):685-93.

13. Sammut E, Searle-Barnes P. Osteopatic Diagnosis. United Kingdom: Stanley Thornes; 1998.

14. Liem T. Cranial osteopathy: principles and practice, 2 ed, United States: Churchill Livingstone; 2004.

15. Dix MR, Hallpike CS. The Pathology, Symptomatology and Diagnosis of Certain Common Disorders of the Vestibular System. Proc R Soc Med. 1952;45(6):341-354.

16. Shim DB, Song CE, Jung EJ, Ko KM, Park JW, Song MH. Benign paroxysmal positional vertigo with simultaneous involvement of multiple semicircular canals. Korean J Audiol. 2014;18(3):126-130.

17. Oliveira AKS, Suzuki FA, Boari L. Is it important to repeat the positioning maneuver after the treatment for benign paroxysmal positional. Braz J Otorhinolaryngol. 2015;81(2):197-201.

18. Sumner A. The Dix-Hallpike Test. J Physiother. 2012; 58(2):131.

19. Traboulsi $H$, Teixido $M$. Qualitative analysis of the Dix-Hallpike maneuver in multi-canal BPPV using a biomechanical model: Introduction of an expanded Dix-Hallpike maneuver for enhanced diagnosis of multi-canal BPPV. World J Otorhinolaryngol Neck Surg. 2017;3(3):163-168.

20. von Brevern $M$, Bertholon $P$, Brandt $T$, Fife $T$, Imai $T$, Nuti $D$ et al. Benign paroxysmal positional vertigo: Diagnostic criteria. J Vestib Res. 2015; 25(3-4):10517.

21. Cerritelli F, Verzella M, Cicchitti L, Alessandro G, Vanacore $\mathrm{N}$. The paradox of sham therapy and 
placebo effect in osteopathy. Medicine (Baltimore). 2016;95(35):e4728.

22. Neto JSM, Stroppa AEZ, Parrera CA, Maximiano WF, Hidalgo CA. Vestibular rehabilitation in patients with benign paroxysmal positional vertigo. Rev CEFAC. 2013;15(3):510-520.

23. Teixeira LJ, Prado GF. Impact of Physical Therapy in vertigo treatment. Rev Neurocienc. 2009;17(2):112118.

24. Brandt T, Bronstein AM. Cervical vertigo. J Neurol Neurosurg Psychiatry. 2001;71(1):8-12.

25. Beardsley C, Skarabot J. Effects of self-myofascial release: A systematic review. J Bodyw Mov Ther. 2015;19(4):747-58.

26. Bai Y, Wang J, Wu J, Dai J, Sha O, Yew DTW et al. Review of Evidence Suggesting That the Fascia Network Could Be the Anatomical Basis for Acupoints and Meridians in the Human Body. Evid
Based Complement Alternat Med. 2011;2011: 260510.

27. Bordoni B, Zanier E. Skin, fascias, and scars: symptoms and systemic connections. J Multidiscip Healthc. 2013;7:11-24.

28. Almeida LC, Barros RLBS, Silva KA, Andrade VLA. Osteopathic treatment effectiveness in quality of life and perception of patients with symptoms of reflux disease refractory gastroesophageal treatment drug. GED. 2014;34(1):10-17.

29. Findley TW. Fascia Research from a Clinician/Scientist's Perspective. Int J Ther Massage Bodyw. 2011;4(4):1-6.

30. Moreira MD, Costa VSP, Melo JJ, Marchiori LLM. Prevalence and association of benign paroxysmal positional vertigo in the elderly. Rev CEFAC. 2014;16(5):1533-1540. 